\title{
PHASE-FIELD MODELING OF $\gamma$ ’ PRECIPITATION IN MULTI-COMPONENT NI-BASE SUPERALLOYS
}

\author{
Tomonori Kitashima ${ }^{1}$, De-Hai Ping ${ }^{1}$, Jincheng Wang ${ }^{2}$, and Hiroshi Harada ${ }^{1}$ \\ ${ }^{1}$ National Institute for Materials Science; 1-2-1 Sengen, Tsukuba, Ibaraki, 305-0047, Japan \\ ${ }^{2}$ Northwestern Polytechnical University; No. 127 West Youyi Road, Xi'an, Shaanxi, 710072, P.R. China
}

Keywords: Phase-Field Modeling, Multi Component, Phase Transformation, Atom Probe Analysis.

\begin{abstract}
To simulate $\gamma$, precipitation in multi-component Ni-base superalloys using the phase-field method, the Gibbs free energy of the $\gamma$ and $\gamma$ ' phases was linked to the CALPHAD method. The free energy curve and phase equilibrium compositions in this work showed good agreement with results obtained using Thermo-Calc calculation, indicating that the model was successfully coupled with the CALPHAD method. Using this coupling method, the $\gamma$ ' precipitation in a quaternary Ni-Al-ReTa and a third-generation Ni-base superalloy TMS-75 systems were simulated. These one-dimensional simulations demonstrated the diffusion-controlled $\gamma$ ' precipitation under local equilibrium with precipitation interactions. According to our atom probe microanalyses, their simulated composition evolutions were reasonable. Such a microstructure modeling technique can contribute to alloy design, process design and even lifetime assessment of high-temperature turbine blades currently in service.
\end{abstract}

\section{Introduction}

Modeling the microstructure evolution of Ni-base superalloys is of considerable importance for alloy design, process design and lifetime assessment of turbine components, e.g. in a virtual turbine [1]. Phase-field simulation has been a powerful tool to predict microstructure evolution in Ni-Al systems [2-8]. Nevertheless, few reports have described its $\gamma$, precipitation in multicomponent Ni-base superalloys, even though recent practical Nibase superalloys incorporate over 10 elements, such as $\mathrm{Al}, \mathrm{Cr}, \mathrm{Mo}$, Re, and Ta [9-11]. The addition of refractory elements, especially $\mathrm{Re}$, confers solid solution strengthening at high temperature. However, the small diffusivity of such refractory elements renders it difficult to predict the elemental distributions in $\gamma$ and $\gamma$, phases and the size distribution of $\gamma$ ' precipitates at the thermal equilibrium state. Therefore, to enable prediction of microstructure morphology in multi-component superalloys, development of a kinetic-modeling technique for multicomponent systems is of considerable importance. Diffusion Controlled Transformation (DICTRA) software has been used to predict the growth rate of a simple-shaped precipitate for the multi-component systems in one-dimensional calculation [12]. However, accompanying the interaction of precipitates across the $\gamma$ phase is difficult because the interface energies, such as interphase domain boundary (IPB) and anti-phase boundary (APB) energies, are not taken into account in the DICTRA. On the other hand, the phase-field model is more attractive to predict complicated morphology evolution because of the characteristics of the so-called diffuse interface model.

One reason for the multi-component difficulty in phase-field modeling is the complexity of deriving the chemical-free-energy surface in the multi-component system, especially for order/disorder phase transformation. In phase-field modeling, the chemical free energy is an important factor that determines the driving force and path of the microstructure evolution. As for a binary Ni-Al superalloy system, some descriptions of the chemical free energy function have been reported, e.g., using the Landau-type polynomial form, the KKS model, and a link to the CALPHAD method [2-8]. However, few descriptions of the multi-component Ni-base superalloy have been proposed $[13,14]$.

In this study, a new phase-field modeling technique that can address $\gamma^{\prime}$ precipitation in multi-component superalloys was developed. This was achieved using the single function formalism of $\gamma / \gamma$ ' Gibbs free energy directly in the CALPHAD method for the chemical free energy in the phase-field method. Using this coupling method, the $\gamma^{\prime}$ precipitation for a quaternary $\mathrm{Ni}-\mathrm{Al}$-Ta-Re superalloy and a third-generation Ni-base superalloy TMS-75 (Ni-6Al-12Co-3Cr-2Mo-5Re-6Ta-6W-0.1Hf, wt\%) were simulated in one dimension. The temporal evolution of element compositions during the growth and coalescence of $\gamma^{\prime}$ precipitates was discussed using results of atom probe analyses.

\section{Modeling}

A thermodynamic description of the $\gamma$ (fcc-A1) and $\gamma$ ' $\left(\mathrm{L} 1_{2}\right)$ phases in the binary $\mathrm{Ni}-\mathrm{Al}$ system was obtained by Ansara et al. using a four-sublattice model [15]. The Gibbs energy of the $\gamma$ ' phase was described by separating it into disordered and ordered contributions in a single function to allow independent evaluation of both $\gamma$ and $\gamma$ ' phase parameters. Zhu et al. [5] proposed a model directly linking a phase-field model with existing thermodynamic databases using the CALPHAD method for the binary Ni-Al system.

This method was extended to multi-component systems using the four-sublattice model. The site fraction of each alloying element $i$ ( $\mathrm{i}=\mathrm{Al}, \mathrm{Co}, \mathrm{Cr}, \mathrm{Mo}, \mathrm{Ni}, \mathrm{Re}, \mathrm{Ta}$ and $\mathrm{W}$ ) on each sublattice $\mathrm{s}$ is denoted as $y_{i}{ }^{(s)}$. The molar Gibbs energy for the $\gamma$ and $\gamma$ ' phases is expressed using the following equations $[15,16]$ : 


$$
\begin{aligned}
G^{\mathrm{fcc}, o r, \mathrm{~L} 1_{2}} & =\sum_{\mathrm{i}} \mathrm{c}_{\mathrm{i}} \mathrm{G}_{\mathrm{i}}^{\mathrm{fcc}}+\mathrm{RT} \sum_{\mathrm{i}} \mathrm{c}_{\mathrm{i}} \ln \mathrm{c}_{\mathrm{i}} \\
& +\sum_{\mathrm{i}} \sum_{\mathrm{j}>\mathrm{i}} \mathrm{c}_{\mathrm{i}} \mathrm{c}_{\mathrm{j}} \sum_{\mathrm{n}=0}^{\mathrm{m}}{ }^{\mathrm{n}} \mathrm{L}_{\mathrm{i}, \mathrm{j}}^{\mathrm{fcc}}\left(\mathrm{c}_{\mathrm{i}}-\mathrm{c}_{\mathrm{j}}\right)^{\mathrm{n}} \\
& +\sum_{\mathrm{i}} \sum_{\mathrm{j}>\mathrm{i}} \sum_{\mathrm{k}>\mathrm{j}} \mathrm{c}_{\mathrm{i}} \mathrm{c}_{\mathrm{j}} \mathrm{c}_{\mathrm{k}} \mathrm{L}_{\mathrm{i}, \mathrm{j}, \mathrm{k}}^{\mathrm{fcc}}+\Delta \mathrm{G}^{\text {ord }}\left(\mathrm{y}_{\mathrm{i}}^{(\mathrm{s})}\right), \\
\Delta \mathrm{G}^{\text {ord }}\left(\mathrm{y}_{\mathrm{i}}^{(\mathrm{s})}\right) & =\Delta \mathrm{G}^{\mathrm{L1} 1_{2}}\left(\mathrm{y}_{\mathrm{i}}^{(\mathrm{s})}\right)-\Delta \mathrm{G}^{\mathrm{L} 1_{2}}\left(\mathrm{y}_{\mathrm{i}}^{(\mathrm{s})}=\mathrm{c}_{\mathrm{i}}\right), \\
\Delta \mathrm{G}^{\mathrm{L1} \mathrm{1}_{2}}\left(\mathrm{y}_{\mathrm{i}}^{(\mathrm{s})}\right) & =\sum_{\mathrm{i}} \sum_{\mathrm{j}} \sum_{\mathrm{k}} \sum_{\mathrm{l}} \mathrm{y}_{\mathrm{i}}^{(1)} \mathrm{y}_{\mathrm{j}}^{(2)} \mathrm{y}_{\mathrm{k}}^{(3)} \mathrm{y}_{\mathrm{l}}^{(4)} \Delta \mathrm{G}_{\mathrm{ijkl}}^{\mathrm{L} 1_{2}} \\
& +\frac{\mathrm{RT}}{4} \sum_{\mathrm{s}} \sum_{\mathrm{i}} \mathrm{y}_{\mathrm{i}}^{(\mathrm{s})} \ln \left(\mathrm{y}_{\mathrm{i}}^{(\mathrm{s})}\right) \\
& +\sum_{\mathrm{s}} \sum_{\mathrm{i}} \sum_{\mathrm{j}>\mathrm{i}} \mathrm{y}_{\mathrm{i}}^{(\mathrm{s})} \mathrm{y}_{\mathrm{j}}^{(\mathrm{s})} \sum_{\mathrm{n}=0}^{1}{ }^{\mathrm{n}} \mathrm{L}_{\mathrm{i}, \mathrm{j}}^{\mathrm{L} 1_{2}}\left(\mathrm{y}_{\mathrm{i}}^{(\mathrm{s})}-\mathrm{y}_{\mathrm{j}}^{(\mathrm{s})}\right)^{\mathrm{n}},
\end{aligned}
$$

where i, j, k and l can be Al, Co, Cr, Mo, Re, Ta, W and Ni on any of the sublattices. $c_{i}$ is a mole-fraction of element $i, R$ is the gas constant and $\mathrm{T}$ is the temperature. $\mathrm{G}_{\mathrm{i}}^{\mathrm{fcc}}$ is a molar Gibbs energy of element $\mathrm{i}$ with the structure of fcc. The first four terms of Eq. (1) correspond to the Gibbs energy of the disordered $\gamma$ phase; $\Delta \mathrm{G}^{\text {ord }}\left(\mathrm{y}_{\mathrm{i}}{ }^{(\mathrm{s})}\right)$ is the ordering energy of the $\gamma$ ' phase as a function of the site fractions. $\Delta G_{i j k l}^{\text {L12 }}$ was expressed in terms of the interchange bond energies (e.g., $\mathrm{U}_{\mathrm{ij}}$ between $\mathrm{i}$ and $\mathrm{j}$ atoms), as

$$
\Delta \mathrm{G}_{\mathrm{ijkl}}^{\mathrm{L1}_{2}}=\mathrm{U}_{\mathrm{ij}}+\mathrm{U}_{\mathrm{ik}}+\mathrm{U}_{\mathrm{il}}+\mathrm{U}_{\mathrm{jk}}+\mathrm{U}_{\mathrm{jl}}+\mathrm{U}_{\mathrm{kl}}+\mathrm{a}_{\mathrm{ijkl}},
$$

where $\mathrm{a}_{\mathrm{ijkl}}$ is a correction variable for some compounds [16]. All variables in Eqs. (1), (3), and (4) are obtainable from the CALPHAD-type assessment [15-18]. Blavette et al. demonstrated by an atom probe study that the partitioning behavior between the Ni-site and the Al-site in the $\gamma$ ' phase depends greatly on the alloying elements [19]. Therefore, the order parameter of each element was newly introduced for the multi-component system. According to the Landau-Lifshitz rule [5, 20, 21], the order parameter of four interpenetrating simple cubic sublattices had three components that can be represented by the site fraction in each sublattice. The order parameters and the composition for each element are defined as

$$
\begin{aligned}
& \eta_{\mathrm{i}}^{1}=\left(\mathrm{y}_{\mathrm{i}}^{(1)}-\mathrm{y}_{\mathrm{i}}^{(2)}-\mathrm{y}_{\mathrm{i}}^{(3)}+\mathrm{y}_{\mathrm{i}}^{(4)}\right) / 4 \mathrm{c}_{\mathrm{i}}, \\
& \eta_{\mathrm{i}}^{2}=\left(\mathrm{y}_{\mathrm{i}}^{(1)}-\mathrm{y}_{\mathrm{i}}^{(2)}+\mathrm{y}_{\mathrm{i}}^{(3)}-\mathrm{y}_{\mathrm{i}}^{(4)}\right) / 4 \mathrm{c}_{\mathrm{i}}, \\
& \eta_{\mathrm{i}}^{3}=\left(\mathrm{y}_{\mathrm{i}}^{(1)}+\mathrm{y}_{\mathrm{i}}^{(2)}-\mathrm{y}_{\mathrm{i}}^{(3)}-\mathrm{y}_{\mathrm{i}}^{(4)}\right) / 4 \mathrm{c}_{\mathrm{i}}, \\
& \mathrm{c}_{\mathrm{i}}=\left(\mathrm{y}_{\mathrm{i}}^{(1)}+\mathrm{y}_{\mathrm{i}}^{(2)}+\mathrm{y}_{\mathrm{i}}^{(3)}+\mathrm{y}_{\mathrm{i}}^{(4)}\right) / 4,
\end{aligned}
$$

where $\eta_{j}^{i}(i=1,2,3, j=A l, C o, C r, M o, R e, T a, W), c_{j}(j=A l, C o$, $\mathrm{Cr}, \mathrm{Mo}, \mathrm{Re}, \mathrm{Ta}, \mathrm{W}$ ) respectively indicate the order parameter and the composition fields. By combining Eqs. (1)-(5), the molar Gibbs energy of the $\gamma$ and $\gamma$ ' phases for the multi-component system can be described using the variables of the order parameter and composition fields for elements $\mathrm{Al}, \mathrm{Co}, \mathrm{Cr}, \mathrm{Mo}, \mathrm{Re}, \mathrm{Ta}, \mathrm{W}$ and $\mathrm{Ni}$.

The total stress-free chemical free energy $\mathrm{F}_{\text {sys }}$ multi in the multicomponent system includes the local free energy density and the interface energy, given as [22]

$\mathrm{F}_{\text {sys }}^{\text {multi }} \equiv \int_{\mathrm{V}}\left(\frac{1}{\mathrm{~V}_{\mathrm{m}}} \mathrm{G}^{\mathrm{fcc}, \mathrm{or}, \mathrm{L1} 1_{2}}+\frac{\alpha}{2} \sum_{\mathrm{j}}\left(\nabla \mathrm{c}_{\mathrm{j}}\right)^{2}+\frac{\beta}{2} \sum_{\mathrm{j}} \sum_{\mathrm{i}=1}^{3}\left(\nabla \eta_{\mathrm{j}}^{\mathrm{i}}\right)^{2}\right) \mathrm{dV}$, (6)

where $V_{m}$ is the molar volume, which was assumed to be constant. In addition, $\alpha$ and $\beta$ respectively signify the gradient energy coefficients for the compositions and order parameters. For this study, to retain simplicity, the composition-dependent elastic energy stemming from the elastic inhomogeneity is not included.

The temporal evolution of the element compositions and order parameters are obtainable by solving the following equations:

$\frac{\partial \mathrm{c}_{\mathrm{i}}}{\partial \mathrm{t}}=\sum_{\mathrm{j}} \nabla \cdot\left(\tilde{\mathrm{M}}_{\mathrm{ij}} \nabla \frac{\delta \mathrm{F}}{\delta \mathrm{c}_{\mathrm{j}}}\right)$,

$\mathrm{i}=\mathrm{j}=\mathrm{Al}, \mathrm{Co}, \mathrm{Cr}, \mathrm{Mo}, \mathrm{Re}, \mathrm{Ta}, \mathrm{W}$,

$\frac{\partial \eta_{\mathrm{i}}^{\mathrm{j}}}{\partial \mathrm{t}}=-\mathrm{L} \frac{\delta \mathrm{F}}{\delta \eta_{\mathrm{i}}^{\mathrm{j}}}$

$\mathrm{i}=\mathrm{Al}, \mathrm{Co}, \mathrm{Cr}, \mathrm{Mo}, \mathrm{Re}, \mathrm{Ta}, \mathrm{W}, \mathrm{j}=1,2,3$

where $\tilde{\mathrm{M}}_{\mathrm{ij}}$ is the so-called chemical mobility with $\mathrm{Ni}$ as the dependent species, and $\mathrm{L}$ is the structural relaxation coefficient. The chemical mobility $\tilde{\mathrm{M}}_{\mathrm{ij}}$ for the $\gamma$ phase is related to the atomic mobilities of the constituent elements, as

$\tilde{\mathrm{M}}_{\mathrm{ij}}=\sum_{\mathrm{l}}\left(\delta_{\mathrm{il}}-\mathrm{c}_{\mathrm{i}}\right)\left(\delta_{\mathrm{jl}}-\mathrm{c}_{\mathrm{j}}\right) \mathrm{c}_{\mathrm{l}} \mathrm{M}_{\mathrm{l}}^{\gamma}$,

where $\delta_{\text {il }}$ and $\delta_{j 1}$ are the Kronecker's delta and $\mathrm{M}_{1} \gamma$ is obtainable from the mobility database [23, 24]. The chemical mobility for the $\gamma$ ' phase was assumed to be identical to that of the $\gamma$ phase. As for parameter $\mathrm{L}$, it was determined as $\tilde{\mathrm{M}}_{\mathrm{AlAl}}=\mathrm{L} \mathrm{a}_{0} / 16$ [25], such that the interface migration velocity was mainly controlled by the diffusion mobility, because the structural relaxation was much faster than the diffusion, with lattice parameter $\mathrm{a}_{0}=3.35 \times 10^{-10} \mathrm{~m}$. Assuming the gradient energy coefficient $\alpha$ to be zero, $\beta=3.75 \times 10^{-16} \mathrm{~J} \cdot \mathrm{m}^{2} / \mathrm{mol}$ for Ni-Al-Re-Ta system, and $\beta=1.13 \times 10^{-15} \mathrm{~J} \cdot \mathrm{m}^{2} / \mathrm{mol}$ for TMS-75 were chosen by fitting the interfacial energy to $10 \mathrm{~mJ} / \mathrm{m}^{2}$, which was close to the experimental and simulated values reported in a Ni-Al system [7,26,27], although very few accurate experimental interface energy data for binary and multi-component Ni-base superalloy systems are available. The assumption that the composition gradient coefficient is zero was a simplification introduced by Vaithyanathan et al. [4]. A Semi-Implicit-Fourier-Spectral- 
Method [28] was used for numerical analyses with a periodical boundary condition. The grid number and grid size were set respectively to 256 and $0.5 \mathrm{~nm}$. At the nucleation stage, small cells of $3 \mathrm{~nm}$ diameter in the field were transformed to $\gamma^{\prime}$ phases with the values of equilibrium order parameters after uniform random values were generated and compared to a certain value.

\section{Experimental Procedures}

For this study, TMS-75 alloy, a third-generation Ni-base single crystal superalloy developed by the National Institute for Materials Science (NIMS) Japan, was investigated using atomprobe analysis in this study. Its nominal composition is Ni-6Al12Co-3Cr-2Mo-5Re-6Ta-6W-0.1Hf in weight \%, whereas $\mathrm{Ni}$ 13.7Al-12.6Co-3.6Cr-1.3Mo-1.7Re-2.1Ta-2.0W-0.01Hf in atomic \% [10,11]. Bar-shaped samples (10mm diameter, $120 \mathrm{~mm}$ length) were cast into single crystal form by directional solidification with the longitudinal axis within $5^{\circ}$ from the [100] pole in the standard stereographic triangle. One bar sample was solution treated for $1 \mathrm{~h}$ at $1300^{\circ} \mathrm{C}$, then by $4 \mathrm{~h}$ at $1320^{\circ} \mathrm{C}$ in the argon gas; then air-cooled. The solution-treated bar sample was then machined into two plate-type samples, which were $20 \mathrm{~mm} \times 9 \mathrm{~mm} \times 2 \mathrm{~mm}$. Subsequently, they were aged at $1100{ }^{\circ} \mathrm{C}$ for $15 \mathrm{~min}$ or $4 \mathrm{~h}$ in air. They were then water quenched.

To avoid preparing atom-probe tips with the oxidized microstructure, the cross-section microstructure of the heat-treated plate-type sample was observed using scanning electron microscopy (SEM). The $\gamma$, depletion and microstructure inhomogeneity in a sample that was heat-treated at $1100^{\circ} \mathrm{C}$ for $4 \mathrm{~h}$ were observed in the range of maximum $30 \mu \mathrm{m}$ from the surface. Square rods of approximately $0.2 \mathrm{~mm} \times 0.2 \mathrm{~mm} \times 10 \mathrm{~mm}$ were cut from the bulk of the heat-treated sample without the oxidized microstructure. These rods were electropolished with $25 \%$ perchloric acid and $75 \%$ acetic acid to sharp needle-shaped specimens initially, with subsequent treatment in $2 \%$ perchloric acid in butoxyethanol. Atom-probe analyses were performed at a tip temperature of about $50 \mathrm{~K}$ under ultrahigh vacuum $\left(<1 \times 10^{-}\right.$ ${ }^{8} \mathrm{~Pa}$ ) with a pulse fraction of 0.2 and a pulse repetition rate of 1500 $\mathrm{Hz}$.

\section{Results and Discussion}

\section{Phase-Field Simulation of the Ni-Al-Re-Ta System}

Figure 1 presents a comparison of the Gibbs energy using the equilibrium order parameters obtained under the condition of $\partial \mathrm{G} / \partial \eta_{i}{ }^{\mathrm{j}}=0$ (i=Al, Ta, Re, $\mathrm{j}=1,2,3$ ), with the result obtained using the Thermo-Calc calculation of the total Gibbs free energy. According to the result, the free energy of the $\gamma$ ' phase was lower than that of the $\gamma$ phase from 0.148 to 0.18 of $\mathrm{C}_{\mathrm{Al}}$. The free energy curve linking to the CALPHAD method agreed well with that of the Thermo-Calc calculation, which indicates that the free energy surface in the multi-component system was successfully derived by linkage to the CALPHAD method. Therefore, the driving force and path of the microstructure evolution are obtainable in the phase-field method according to the CALPHAD method, even in a complex higher-component system.

Using the free energy linking to the CALPHAD method, a onedimensional simulation for the $\gamma$ ' precipitation of a Ni-16.5at\% Al-1at\%Re-2at\%Ta superalloy at $1100^{\circ} \mathrm{C}$ was carried out as shown in Fig. 2. Ta and Re were rich in the $\gamma^{\prime}$ and $\gamma$ phases, respectively. After nuclei formed, the precipitates were supersaturated with $\mathrm{Al}$ of 0.19 , as presented in Fig. 2(b). Fig. 2(c) shows that the supersaturation then decreased continuously. The local equilibrium of Re at the $\gamma / \gamma$ ' interface, as demonstrated by results of atom probe studies [29, 30], was confirmed in Fig. 2(c). In Figs. 2(b) and 2(c), precipitate B is closer to $C$ than to A. However, precipitates $\mathrm{A}$ and $\mathrm{B}$ subsequently merged and decreased the interface energy, as presented in Fig. 2(d) because the domain of precipitate $A$ was identical to that of $B$, whereas those of B and C differed, not forming an APB. The APB energy was usually high: twice as large as the IPB energy.

Regarding the coalescence of precipitates $\mathrm{A}$ and $\mathrm{B}$, after two spikes of Re, denoted by D and E, came near each other, a narrow $\gamma$ channel formed with a supersaturated Re composition, which piled up as a result of $\mathrm{D}$ and $\mathrm{E}$, thereby prompting a higher Re spike, presented as F in Fig. 2(d). Moreover, the small diffusivity of Re made the spike $\mathrm{F}$ decrease slowly in the $\gamma$ ' phase. The phase compositions then gradually reached the equilibrium composition. The spike of the element composition accompanied by the precipitate coalescence, such as that shown by F in Fig. 2(d), was probably common for alloying elements, although the diffusion rate of the spike depended largely on the element diffusivity.

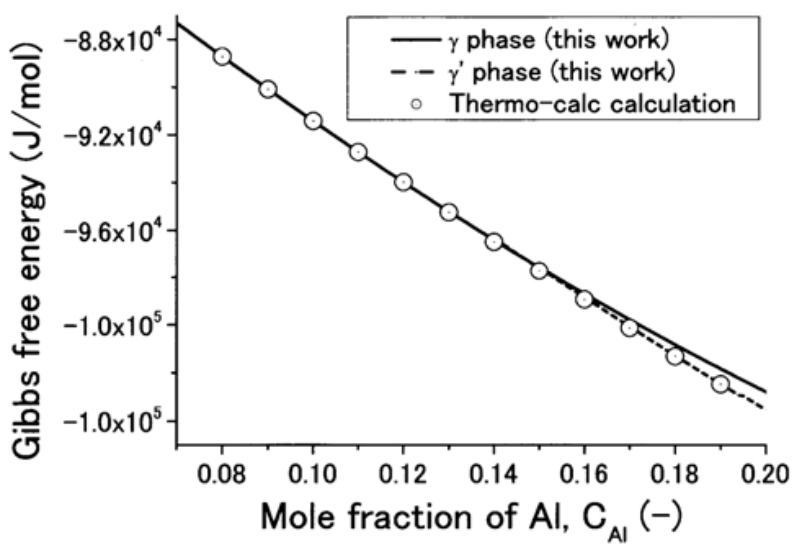

Figure 1 Comparison of free energy obtained in this work with the calculated result obtained using Thermo-Calc software. 

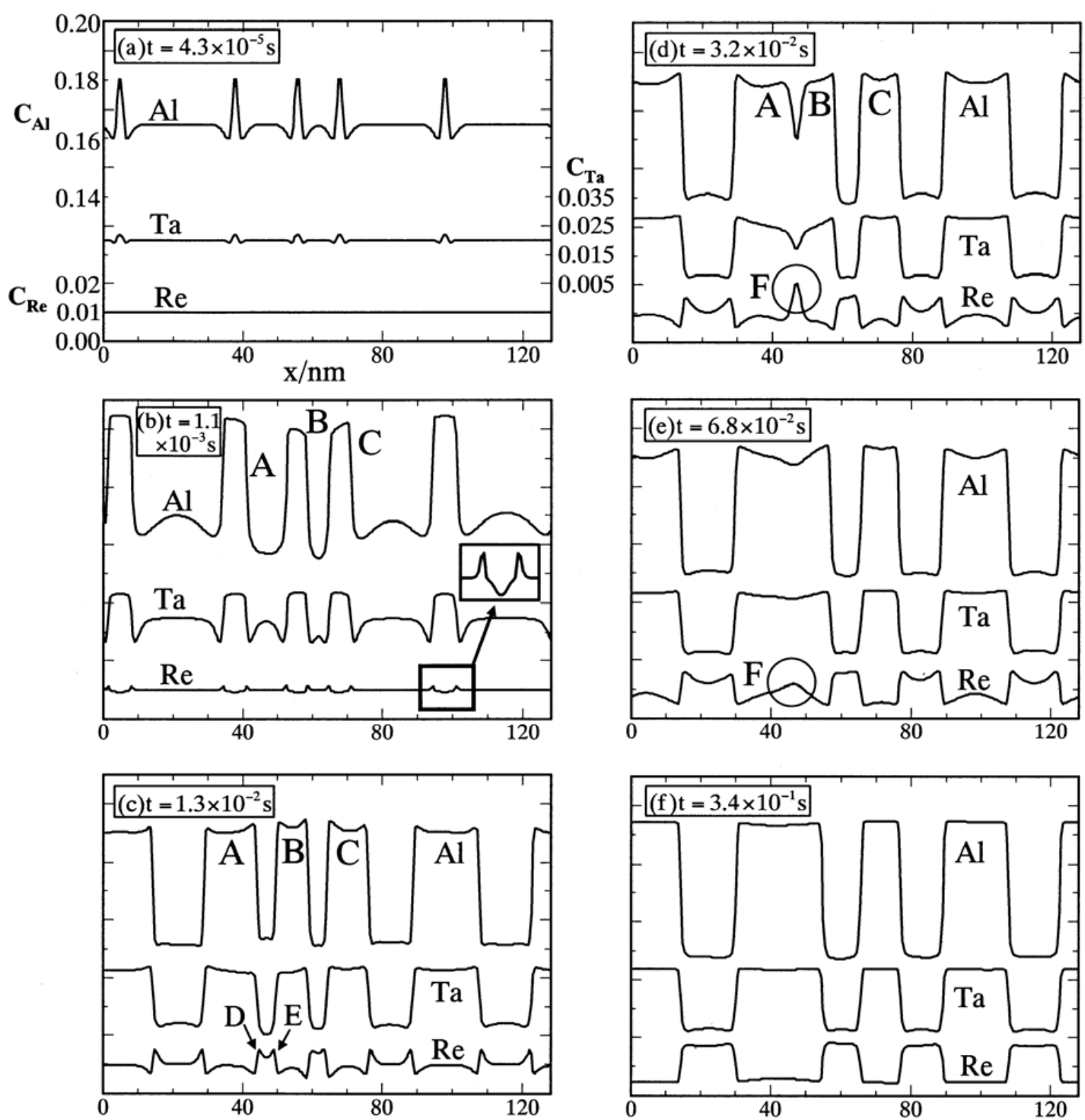

Figure 2 Temporal evolution of Al, Re, and Ta composition profiles in a Ni-16.5at\% Al-1at\%Re-2at\%Ta superalloy at $1100^{\circ} \mathrm{C}$.

\begin{tabular}{|c|c|c|c|c|c|c|c|c|c|}
\hline & & Co & $\mathrm{Cr}$ & Mo & $\mathrm{W}$ & $\mathrm{Al}$ & $\mathrm{Ta}$ & $\mathrm{Re}$ & $\mathrm{V}_{\mathrm{f}}$ \\
\hline \multirow{2}{*}{ Calculation (this work). } & $\gamma$ & 6.3 & 1.3 & 0.4 & 0.7 & 18.9 & 3.5 & 0.3 & \multirow{2}{*}{0.51} \\
\hline & $\gamma$ & 19.1 & 6.0 & 2.2 & 3.4 & 8.4 & 0.4 & 3.1 & \\
\hline \multirow{2}{*}{$\begin{array}{l}\text { Observation } \\
\text { by Yokokawa et al.[11]. }\end{array}$} & $\gamma^{\prime}$ & 10.0 & 1.8 & 0.7 & 1.6 & 16.9 & 2.7 & 0.4 & \multirow{2}{*}{$\begin{array}{l}0.55 \\
{[10]}\end{array}$} \\
\hline & $\gamma$ & 18.2 & 6.4 & 1.9 & 2.2 & 8.9 & 1.0 & 3.1 & \\
\hline
\end{tabular}

Table 1 Comparison of the predicted and the observed $\gamma$ and $\gamma$ ' phase compositions of TMS-75 at $1100^{\circ} \mathrm{C}$. 
In Fig. 2(f), the phase compositions at $x=10 \mathrm{~nm}$ in the $\gamma^{\prime}$ phase and at $\mathrm{x}=115 \mathrm{~nm}$ in the $\gamma$ phase were $\mathrm{Ni}-18.4 \mathrm{at} \% \mathrm{Al}-0.472 \mathrm{at} \% \mathrm{Re}-$ 2.87at\%Ta and Ni-13.8at\%Al-1.70at\%Re-0.792at\%Ta, respectively. These values agreed well with the equilibrium compositions calculated using Thermo-Calc software, which were Ni-18.5at\%Al-0.450at\%Re-2.86at\%Ta for the $\gamma^{\prime}$ phase and Ni13.8at\%Al-1.77at\%Re-0.792at\%Ta for the $\gamma$ phase. Consequently, the present model demonstrated $\gamma$ ' precipitation with the growth and interaction of precipitates in the quaternary system, by coupling with thermodynamic description in the CALPHAD method. In the next section, a practical alloy, TMS75 , is simulated.

\section{$\underline{\text { Phase-Field Simulation and Atom Probe Analysis of TMS-75 }}$}

A third-generation Ni-base superalloy, TMS-75 contains Al, Co, $\mathrm{Cr}, \mathrm{Mo}, \mathrm{Re}, \mathrm{Ta}, \mathrm{W}$, and Hf. Its nominal composition is Ni-6Al12Co-3Cr-2Mo-5Re-6Ta-6W-0.1Hf in weight \%, and Ni-13.7Al12.6Co-3.6Cr-1.3Mo-1.7Re-2.1Ta-2.0W-0.01Hf in atomic \% $[10,11]$. For simplification, Hf was excluded from present calculations. At first, $\gamma^{\prime}$ volume fraction, $\gamma$ and $\gamma^{\prime}$ phase compositions were compared between the calculated prediction and experimental observations as shown in Table 1. According to Murakumo et al.[10], the observed $\gamma^{\prime}$ volume fraction of TMS-75 was about 0.55 at $1100^{\circ} \mathrm{C}$. On the other hand, the present CALPHAD predicted 0.51 of the volume fraction for this alloy. Yokokawa et al. [11] measured the $\gamma$ and $\gamma$, phase compositions using an electron probe $\mathrm{x}$-ray microanalyzer (EPMA), followed by water quenching after heat treatment at $1100^{\circ} \mathrm{C}$ as shown in Table 1 . Both the predicted and measured compositions and partitioning behavior show good agreement, even though the phase-equilibrium information for higher component systems are determined from the extrapolation of binary, ternary and quaternary systems in the CALPHAD method. The observed $\gamma$ ' composition of Co is slightly larger than the predicted one. $\mathrm{W}$ is preferred to partition into much more $\gamma$ phase in the calculated result. In this alloy, $\mathrm{Al}$ and Ta were rich in the $\gamma$ ' phases, whereas Co, Cr, Mo, Re, and $\mathrm{W}$ were rich in the $\gamma$ phase.

To investigate the temporal evolution of alloying element compositions experimentally, microstructural observation and atom-probe microanalyses of TMS-75 were performed. Figure 3 shows microstructures of TMS-75 after heat treatment at $1100^{\circ} \mathrm{C}$ for $15 \mathrm{~min}$ (a) or $4 \mathrm{~h}$ (b). In the alloy heat treated for $15 \mathrm{~min}$, fine spherical $\gamma^{\prime}$ precipitates were observed because the growth of $\gamma^{\prime}$ phases at this stage was mainly controlled by the increasing isotropic interfacial energy. In the alloy that had been heat treated for $4 \mathrm{~h}$ depicted in Fig. 3(b), the morphology of grown $\gamma^{\prime}$ precipitates was aligned cuboidally along a certain orientation.

Figure 4 shows the composition profiles obtained using atomprobe analyses for these alloys: heat-treated for $15 \mathrm{~min}$ (a) or $4 \mathrm{~h}$ (b). In the alloy that was heat treated for $15 \mathrm{~min}$, small $\gamma^{\prime}$ precipitates, where the $\mathrm{Al}$ mole fraction is about 0.2 , were easily detected. At the $\gamma / \gamma$, interface denoted by $\mathrm{I}$, the local equilibrium was significantly observed, especially for Re. In addition, $\mathrm{Al}$ and $\mathrm{Ta}$ in a narrow $\gamma$ channel next to small precipitates shown by arrows $\mathrm{G}$ and $\mathrm{H}$ in Fig. 4 (a) were depleted. On the other hand, Co and $\mathrm{Cr}$ and other refractory elements such as Mo, Re, and $\mathrm{W}$ supersaturated in its $\gamma$ phase. In Fig. 4(b), the local equilibrium was still observable at the interfaces indicated by arrows of $\mathrm{J}$ and $\mathrm{K}$ because that the $\gamma^{\prime}$ phase remained under the growth process at this stage, i.e. the system had not reached a thermodynamic equilibrium state. These phenomena were simulated using the phase-field method.

Figure 5 shows snapshots of simulated temporal evolution of alloying element composition profiles in TMS- 75 at $1100^{\circ} \mathrm{C}$. At the initial stage after nucleation, $\mathrm{Al}$ in a narrow $\gamma$ channel shown by an arrow $\mathrm{L}$ in Fig. 5(a) was depleted. The $\gamma$ formers, such as $\mathrm{Co}, \mathrm{Cr}, \mathrm{Mo}, \mathrm{Re}$, and $\mathrm{W}$, supersaturated in the $\gamma$ phase. In the $\gamma$ ' growth process presented in Fig. 5(b), almost all elements at the interfaces of small precipitates had almost equilibrium compositions, except for Re and W. On the other hand, at the interface of $\gamma$ ' and large $\gamma$ phases shown by an arrow $M$, a local equilibrium was confirmed for all elements. In Figs. 5(c) and 5(d), a small $\gamma$ ' phase shrank and disappeared, as shown by an arrow N. Such a so-called Ostwald-ripening process was observed in the simulation. Its Re profile was very characteristic, like a spinning top as presented in Fig. 5(c) because the Re's local equilibria at $\gamma / \gamma$, interfaces of both sides of the precipitate merged. Therefore, the simulated temporal evolution of composition profiles at the $\gamma / \gamma$, interface agreed well qualitatively with the experimental observations, considering the simplicity of its multi-component model. In general, it is difficult to detect, experimentally, such temporal evolution of compositions during $\gamma^{\prime}$, coalescence and Ostwald-ripening process. Such multi-component simulation is necessary to predict the microstructure evolution.

It is noteworthy that the present simulated system incorporated no composition-dependent elastic energy stemming from the elastic inhomogeneity for simplification. Such elastic energy would affect microstructure morphology such as the $\gamma^{\prime}$ precipitate alignment, precipitate dispersion, and precipitate shapes. Moreover, the simulated system size is smaller than the real one because of the computational scheme and model limits. Therefore, the growth rate of the $\gamma^{\prime}$ phase does not correspond quantitatively to experimental results. Such incorporation of elastic energy effects and increase of the length scale are our next objectives. Nevertheless, it was concluded from results of this study that the present modeling technique is very useful to design new alloys as well as process conditions. 

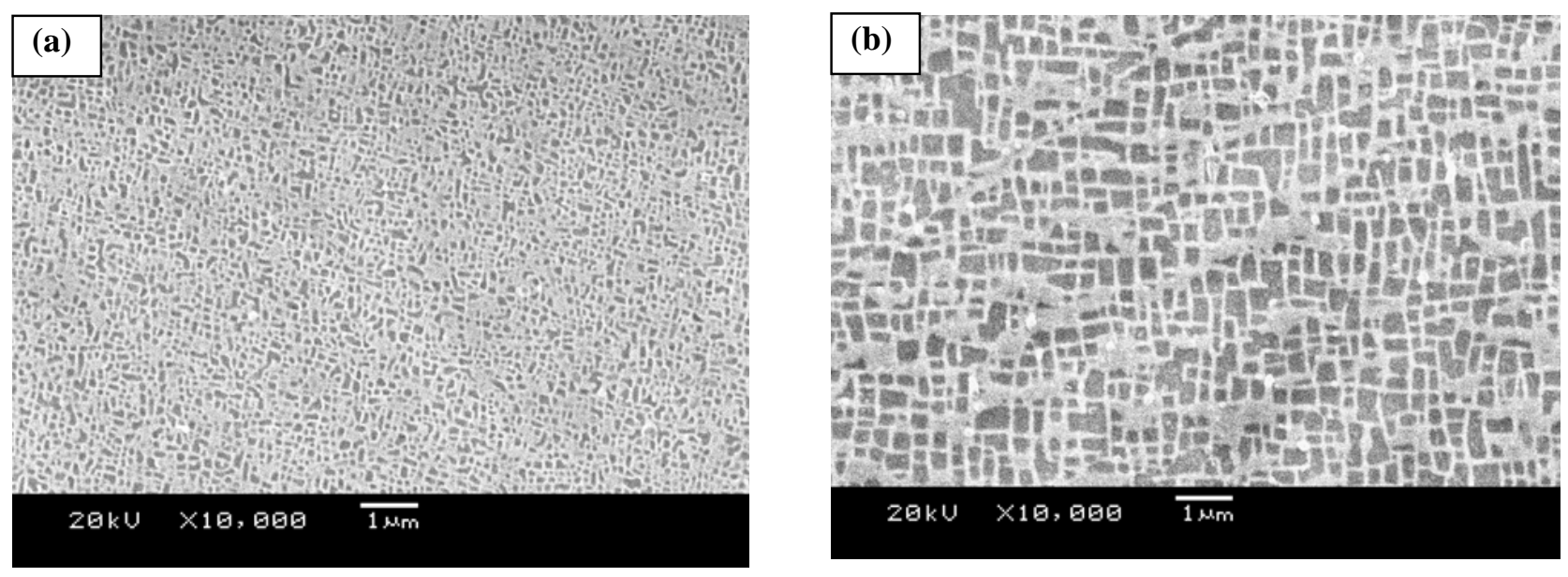

Figure 3 SEM images of TMS-75 after heat treatment at $1100^{\circ} \mathrm{C}$ for $15 \mathrm{~min}$ (a) or $4 \mathrm{~h} \mathrm{(b).}$

(a) H.T. $1100^{\circ} \mathrm{C} 15 \mathrm{~min}+\mathrm{WQ}$

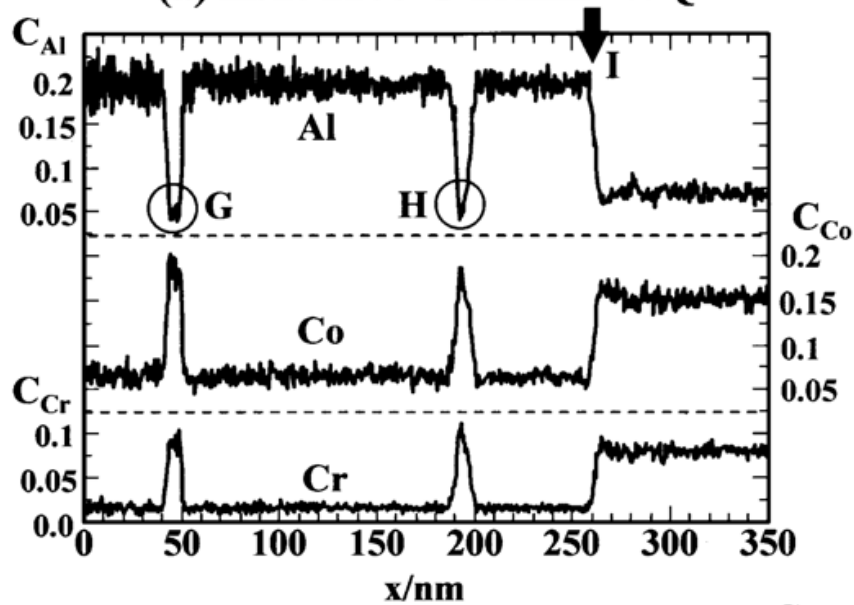

$\mathrm{C}_{\mathrm{M} 0}$

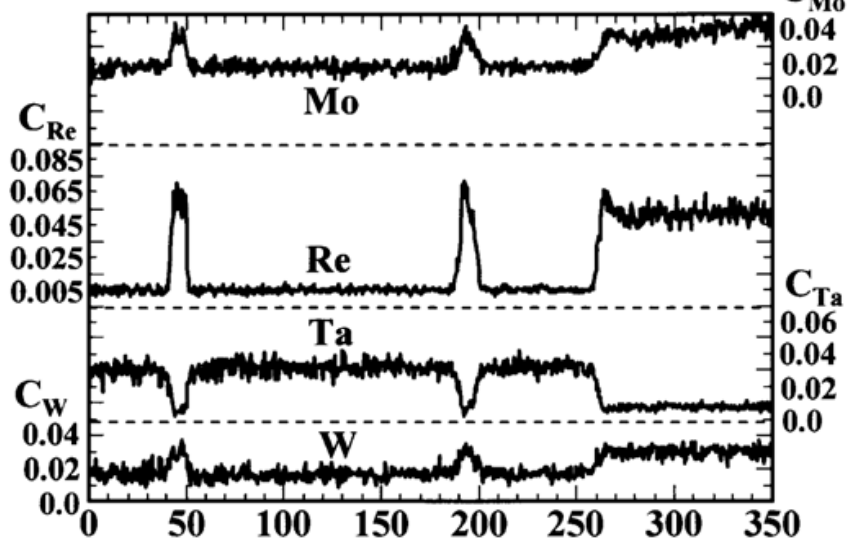

(b) H.T. $1100^{\circ} \mathrm{C} 4 \mathrm{~h}+\mathrm{WQ}$
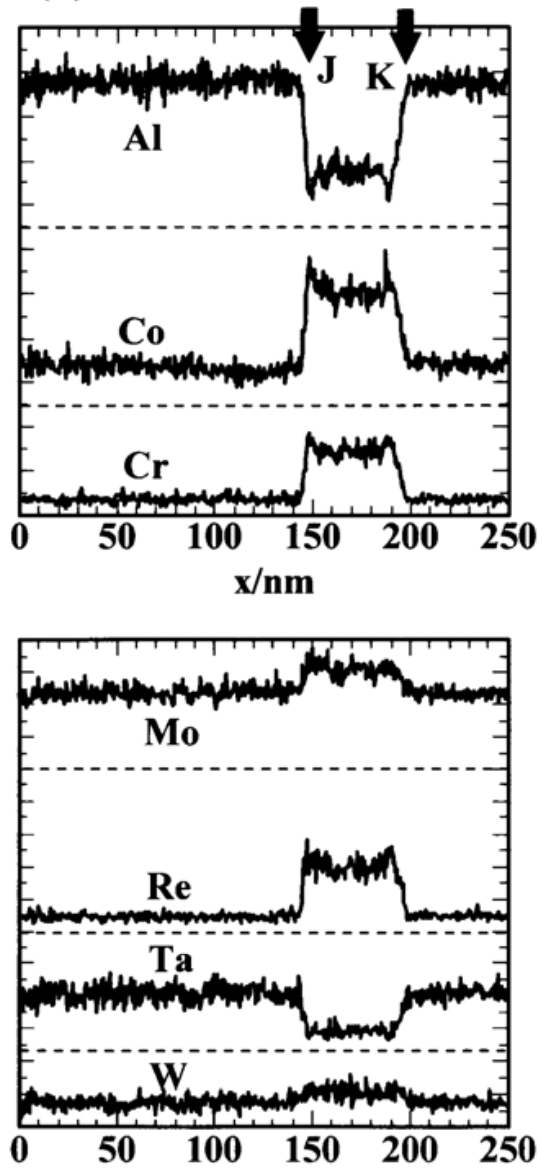

Figure 4 Composition profiles of TMS-75 obtained using atom-probe analyses: heat treated at $1100^{\circ} \mathrm{C}$ for $15 \mathrm{~min}$ (a) or for $4 \mathrm{~h}(\mathrm{~b})$. 
(a) $\mathrm{t}=1.6 \times 10^{-2} \mathrm{~s}$

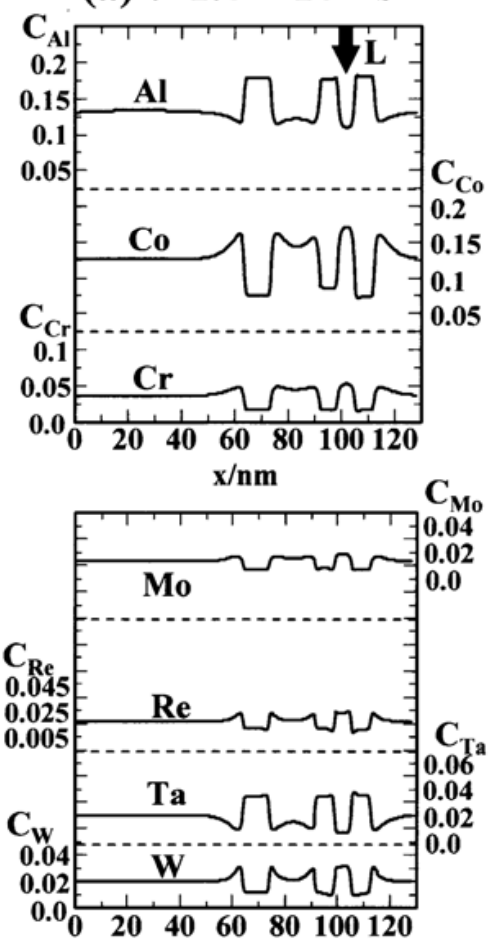

(c) $\mathrm{t}=7.1 \times 10^{-1} \mathrm{~s}$

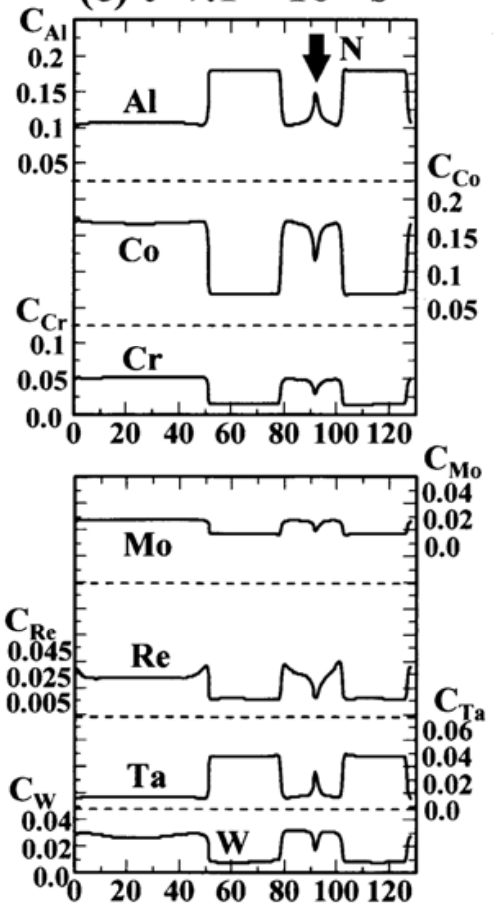

(b) $\mathrm{t}=1.7 \times 10^{-1} \mathrm{~s}$
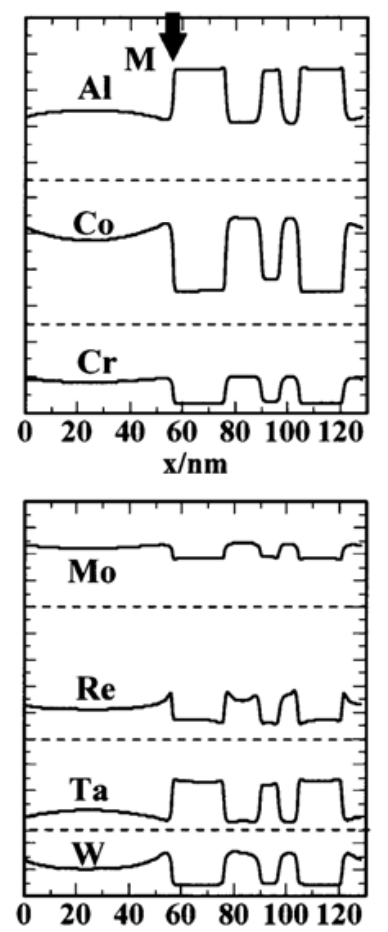

(d) $\mathrm{t}=\mathbf{2 . 8 \mathrm { s }}$
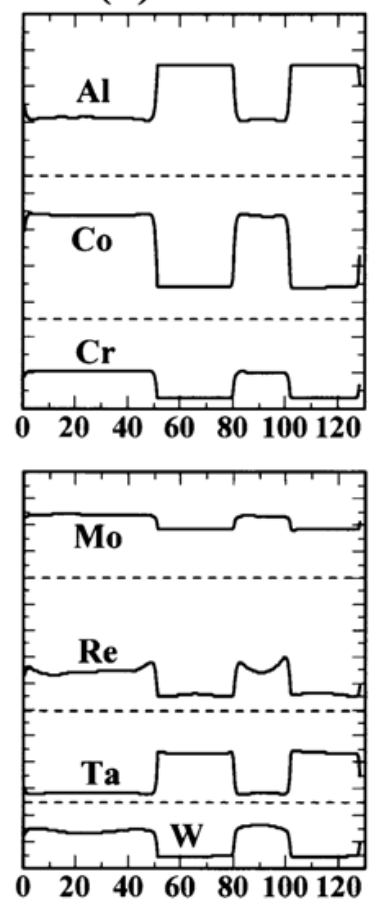

Figure 5 Temporal evolution of alloying-element composition profiles in TMS-75 at $1100^{\circ} \mathrm{C}$. 


\section{Conclusions}

New multi-component phase-field modeling coupled with the CALPHAD method was developed by adopting the $\gamma / \gamma$ ' single formalism of the Gibbs free energy in the CALPHAD for the chemical free energy in the phase-field method. Using this coupling method, the $\gamma$ ' phase precipitation in a quaternary $\mathrm{Ni}$ Al-Re-Ta system and a third-generation superalloy TMS-75 was simulated. These simulations demonstrated the local equilibrium at $\gamma / \gamma$, interfaces, growth of $\gamma^{\prime}$ precipitates, precipitate interactions such as coalescence, and the Ostwald-ripening process. The simulated temporal evolution of composition profiles was qualitatively reasonable, compared to experimental observations using atom-probe analyses. This modeling technique can contribute to alloy design, process design and lifetime assessment of high-temperature turbine blades currently in service.

\section{Acknowledgement}

The authors acknowledge Mr. Tomohito Kimura at Shibaura Institute of Technology, Japan for assistance with experiments.

\section{References}

1. T. Yokokawa, H. Saeki, Y. Fukuyama, T. Yoshida, and H. Harada, "The virtual gas turbine system for alloy assessment," Superalloys 2004, 859-866.

2. D.Y. Li, and L.Q. Chen, "Computer simulation of morphological evolution and rafting of $\gamma$ ' particles in Nibased superalloys under applied stresses,” Scripta Materialia, 37 (1997), 1271-1277.

3. Y. Wang, D. Banerjee, C.C. Su, and A.G. Khachaturyan, "Field kinetic model and computer simulation of precipitation of $\mathrm{L} 1_{2}$ ordered intermetallics from F.C.C solid solution," Acta Materialia, 46 (1998), 2983-3001.

4. V. Vaithyanathan, and L.Q. Chen, "Coarsening of ordered intermetallic precipitates with coherency stress," Acta Materialia, 50 (2002), 4061-4073.

5. J.Z. Zhu, Z.K. Liu, V. Vaithyanathan, and L.Q. Chen, "Linking phase-field model to CALPHAD: application to precipitate shape evolution in Ni-base superalloys," Scripta Materialia, 46 (2002), 401-406.

6. J.Z. Zhu, T. Wang, A.J. Ardell, S.H. Zhou, Z.K. Liu, and L.Q. Chen, "Three-dimensional phase-field simulations of coarsening kinetics of $\gamma^{\prime}$ particles in binary Ni-Al alloys," Acta Materialia, 52 (2004), 2837-2845.
7. J.C. Wang, M. Osawa, T. Yokokawa, H. Harada, and M. Enomoto, "Modeling the microstructural evolution of Ni-base superalloys by phase field method combined with CALPHAD and CVM," Computational Materials Science, 39 (2007), 871879.

8. Y.H. Wen, B. Wang, J.P. Simmons, and Y. Wang, “A phasefield model for heat treatment applications in Ni-based alloys,” Acta Materialia, 54 (2006), 2087-2099.

9. Y. Koizumi, T. Kobayashi, T. Yokokawa, J.X. Zhang, M. Osawa, H. Harada, Y. Aoki, and M. Arai, "Development of next generation Ni-base single crystal superalloys," Superalloys 2004, 35-43.

10. T. Murakumo, T. Kobayashi, Y. Koizumi, and H. Harada, "Creep behaviour of Ni-base single-crystal superalloys with various $\gamma^{\prime}$ volume fraction,” Acta Materialia, 52 (2004), 3737-3744.

11. T. Yokokawa, M. Osawa, K. Nishida, T. Kobayashi, Y. Koizumi, and H. Harada, "Partitioning behavior of platinum group metals on the $\gamma$ and $\gamma^{\prime}$ phases of Ni-base superalloys at high temperatures,” Scripta Materialia, 49 (2003), 1041-1046.

12. John Agren, "Computer simulations of diffusional reactions in complex steels,” ISIJ Internaional, 32 (1992), 291-296.

13. U. Grafe, U. Bottger, J. Tiaden, and S.G. Fries, “Coupling of multicomponent thermodynamic databases to a phase field model: application to solidification and solid state transformations of superalloys," Scripta Materialia, 42 (2000), 1179-1186.

14. Toshiyuki Koyama, "Phase-field simulation of the microstructure changes in Ni and Co base superalloys," (Paper presented at the JSME 19th Computational Mechanics Conference, Nagoya, Japan, 3-5 November, 2006). [in Japanese]

15. I. Ansara, N. Dupin, H.L. Lukas, and B. Sundman, "Thermodynamic assessment of the Al-Ni system," Journal of Alloys and Compounds, 247 (1997), 20-30.

16. N. Dupin, I. Ansara, and B. Sundman, "Thermodynamic reassessment of the ternary system Al-Cr-Ni," Calphad, 25 (2001), 279-298.

17. A.T. Dinsdale, "SGTE data for pure elements," Calphad, 15 (1991), 317-425.

18. Ursula R. Kattner, "The thermodynamic modeling of multicomponent phase equilibria,” JOM, 49 (1997), 14-19. 
19. D. Blavette, and A. Bostel, "Phase composition and long range order in $\gamma^{\prime}$ phase of a nickel base single crystal superalloy CMSX2: An atom probe study," Acta Metallurgica, 32 (1984), 811-816.

20. L.D. Landau, and E.M. Lifshitz, Statistical Physics $3^{\text {rd }}$ Edition Part 1, (Pergamon, London, 1980), 446.

21. Z.W. Lai, "Theory of ordering dynamics for Cu3Au," Physical Review B, 41 (1990), 9239-9256.

22. J.W. Cahn, and L.E. Hilliard, "Free energy of a nonuniform system. I. Interfacial free energy,” The Journal of Chemical Physics, 28 (1958), 258-267.

23 M.S.A Karunarate, D.C. Cox, P. Carter, and R.C. Reed, "Modelling of the microsegregation in CMSX-4 superalloy and its homogenization during heat treatment," Superalloys 2000, 263-272.

24. C.E. Campbell, W.J. Boettinger, and U.R. Kattner, "Development of a diffusion mobility database for Ni-base superalloys” Acta Materialia, 50 (2002), 775-792.

25. R. Poduri, and L.Q. Chen, "Computer simulation of morphological evolution and coarsening kinetics of $\delta^{\prime}\left(\mathrm{Al}_{3} \mathrm{Li}\right)$ precipitates in Al-Li alloys,” Acta Materialia, 46 (1998), 3915-3928.

26. A.J. Ardell, "The effect of volume fraction on particle coarsening: theoretical considerations,” Acta Metallurgica, 20 (1972), 61-71.

27. Alan J. Ardell, "Interfacial free energies and solute diffusivities from data on Ostwald ripening," Interface Science, 3 (1995) 119-125.

28. L.Q. Chen, and J. Shen, "Applications of semi-implicit Fourier-spectral method to phase-field equaitons," Computer Physics Communication, 108 (1998), 147-158.

29. H. Murakami, P.J. Warren, and H. Harada, "Atom-probe microanalysis of some Ni-base single crystal superalloys," (Paper presented at the $3^{\text {rd }}$ International Charles Parsons Turbine Conference, Newcastle upon Tyne, UK, 25-27 April 1995), 343-350.

30. P.J. Warren, A. Cerezo, and G.D.W. Smith, “An atom probe study of the distribution of rhenium in a nickel-based superalloy,” Materials Science and Engineering A, 250 (1998), 88-92. 